Classificatory Matrix for Linguistic Varieties" (319-27); B. Pearson, "Paradigms and Revolutions in Linguistics" (384-90); B. L. Dubois's "A Cloze Study of Verb Usage in Context: Anglos and Chicanos" (604-14); A. W. Read's "The Numerical Naming of People" (615-24); B. Phillips's "A Calculus of Cohesion" (627-37); T. H. Wilbur's "The Grammar of the Basque Proverb" (638-41); and A. Makkai's "The Meaning of Noel Coward's 'Venice," " an English text with Italian rhymes $(670-79) \cdot(\mathrm{DH})$

Richard Slobodin, W. H. R. Rivers. (Leaders of Modern Anthropology Series). New York: Columbia University Press, 1978. Pp. xvi +295 .

This welcome addition to the Leaders of Modem Anthropology series includes discussion of Rivers's development of the genealogical method, his studies of the evolution of color terminology, and his anonymous verses, "Anthropological Thoughts" (reprinted here), as points of ethnolinguistic interest. All are set of course in the context of Rivers's career and reputation. (D. H.)

EVENT: HUMOR CONFERENCE at Arizona State University

DATE: April I, 1982 (April Fool's Day)

DEADLINE FOR PROPOSALS: July 4,198 I

THEME: The Language of Humor and the Humor of Language

SPONSOR: Western Humor and Irony Membership (WHIM), an affiliate of Workshop Library on World Humour (WLWH)

WHIM EXECUTIVE COMMITTEE: Frank D'Angelo, Kenneth Donelson, Alleen Nilsen, Don Nilsen, and Nick Salerno

FOR FURTHER INFORMATION CONTACT: Don L. F. Nilsen, Chair, 1982 WHIM Conference, English Department, Arizona State University, Tempe, AZ 8528I

ERRATA. In Vol. 9, no. 1, page 40, the article "Language and ethnicity" (1977) should have been attributed to J. Fishman. On page 39, the word "unadulterated" (second line from the bottom) should read "adulterated." Finally, on page 37, "Am Embo septuagenerian" should read "An Embo septuagenarian. "Language in Sociery regrets the oversights.

\title{
PUBLICATIONS RECEIVED
}

American education research journal 17(3) (Fall 1980).

American Indian culture and research journal 4(1-2) (1980). Special issue on American Indian translation, edited by $K$. Lincoln.

American anthropologist 82(1) (March 1980). Including D. Falk, "Language, handedness, and primate brains: Did the Australopithecines sign?" 72-78. Argues that language had been selected for by the time bipedalism was achieved and that, contrary to the gestural hypothesis, righthandedness (which could not have preceded freeing of the hands) succeeded speech. Also 82(2) (June 1980).

Anthropological linguistics 2 I(5) (May 1979). Including S. O. Murray, "The art of gay insulting," 2II-23; L. B. Breitborde, "Jacaltec kinship semantics: The rule of uniform reciprocals, covert classes, and their consequences," 232-55. Also 21(6) (September 1979); 21(7) (October 1979). Including E. C. Y. Kuo, "Measuring communicativity in multilingual societies: The cases of Singapore and West Malaysia," 328-40; E. S. Grobsmith. "Styles of speaking: An analysis of Lakota communicative alternatives, “ 355-61; $21(8)$ (November 1979); 2 I(9) (December 1979); 22(1) (January 1980); 22(2) (February 1980); 22(3) (March 1980); 22(4) (April 1980). Including M. Cain. "Edward Sapir and Gestalt psychology." 141-50; S. V. Parasher, "Mother tongueEnglish diglossia: A case study of educated Indian bilinguals' language use," I5I-62; S. O. Murray, "Lexical and institutional elaboration: The species homosexual in Guatemala," 177-85; 22(5) (May 1980). Including J. E. Grimes, "Huichol life form classification I: Animals," 187-200 (an important contribution to understanding the ways in which linguistic expressions, other than covering terms, may classify natural phenomena); M. R. Zughoul, "Diglossia in 